\title{
Article \\ Nanovesicles from Organic Agriculture-Derived Fruits and Vegetables: Characterization and Functional Antioxidant Content
}

\author{
Mariantonia Logozzi *, ${ }^{\star}$, Rossella Di Raimo ${ }^{+}$(D), Davide Mizzoni (D) and Stefano Fais * \\ Department of Oncology and Molecular Medicine, Istituto Superiore di Sanità, Viale Regina Elena 299, \\ 00161 Rome, Italy; rossella.diraimo@iss.it (R.D.R.); davide.mizzoni@iss.it (D.M.) \\ * Correspondence: mariantonia.logozzi@iss.it (M.L.); stefano.fais@iss.it (S.F.); Tel.: +39-064-9902-436 (M.L.); \\ +39-064-9903-195 (S.F.); Fax: +39-064-9902-436 (M.L. \& S.F.) \\ + These authors contributed equally to this work.
}

check for updates

Citation: Logozzi, M.; Di Raimo, R.; Mizzoni, D.; Fais, S. Nanovesicles from Organic Agriculture-Derived Fruits and Vegetables:

Characterization and Functional Antioxidant Content. Int. J. Mol. Sci. 2021, 22, 8170. https://doi.org/ $10.3390 /$ ijms 22158170

Academic Editor: Maria

Luisa Balestrieri

Received: 13 July 2021

Accepted: 27 July 2021

Published: 29 July 2021

Publisher's Note: MDPI stays neutral with regard to jurisdictional claims in published maps and institutional affiliations.

Copyright: (c) 2021 by the authors. Licensee MDPI, Basel, Switzerland. This article is an open access article distributed under the terms and conditions of the Creative Commons Attribution (CC BY) license (https:// creativecommons.org/licenses/by/ $4.0 /)$.

\begin{abstract}
Dietary consumption of fruits and vegetables is related to a risk reduction in a series of leading human diseases, probably due to the plants' antioxidant content. Plant-derived nanovesicles (PDNVs) have been recently receiving great attention regarding their natural ability to deliver several active biomolecules and antioxidants. To investigate the presence of active antioxidants in fruits, we preliminarily analyzed the differences between nanovesicles from either organic or conventional agriculture-derived fruits, at equal volumes, showing a higher yield of nanovesicles with a smaller size from organic agriculture-derived fruits as compared to conventional ones. PDNVs from organic agriculture also showed a higher antioxidant level compared to nanovesicles from conventional agriculture. Using the PDNVs from fruit mixes, we found comparable levels of Total Antioxidant Capacity, Ascorbic Acid, Catalase, Glutathione and Superoxide Dismutase 1. Finally, we exposed the nanovesicle mixes to either chemical or physical lytic treatments, with no evidence of effects on the number, size and antioxidant capacity of the treated nanovesicles, thus showing a marked resistance of PDNVs to external stimuli and a high capability to preserve their content. Our study provides for the first time a series of data supporting the use of plant-derived nanovesicles in human beings' daily supplementation, for both prevention and treatment of human diseases.
\end{abstract}

Keywords: plant-derived nanovesicles; organic agriculture; antioxidants; natural bioactives

\section{Introduction}

The beneficial effects of food and its bioactive components on human health and disease are widely recognized [1-5]; in fact, this knowledge covers a huge part of the pharmaceutical market [6,7]. Unfortunately, the vast majority of the food-derived products come from chemical extractions, which highly impairs their bioavailability [5]. Recently, it has been reported that food-derived nanovesicles can enhance the efficacy of natural compounds through a marked improvement in their bioavailability, probably due to the natural protection exerted by the nanovesicles on their bioactive content [8]. Plant-derived nanovesicles (PDNVs) are small vesicles surrounded by a lipid-enriched membrane and containing different natural compounds, including vitamins, antioxidants, proteins, nucleic acids and other metabolites. All these bio-compounds have shown to maintain their biological activities when uploaded to target cells. The mean size of the nanovesicles ranges between $250 \mathrm{~nm}$ (grapefruit and ginger EVs) [8-10] and $400 \mathrm{~nm}$ (grape) [9,11]. This may depend on the fruit or vegetables under observation; for instance, nanovesicles isolated from carrots are more heterogeneous, with sizes ranging from $100 \mathrm{~nm}$ to $1000 \mathrm{~nm}[9,12]$. Only recently we have collected more information on the biogenesis of plant-derived nanovesicles [13]. This first report showed, by TEM analysis, the presence of Multivesicular Bodies (MVBs) on barley leaf cells attacked by a fungus. More recently, it has been 
postulated that MVBs participate in the intake of nutrients from apoplast, and of damaged membranes and deleterious materials originating from the oxidative microburst [14]. PDNVs play several crucial roles in plant cell homeostasis, including unconventional plant cell wall remodeling [15] and plant defense [16-18]. In fact, these nanovesicles have evolved in plants as a way to communicate between both plant cells and other plants or animals $[12,16]$. Nanovesicles were found both in the xylem and phloem of woody plants, supporting their role in the storage and transport of endoglucanases [19], essential for plant growth [20]. Further studies have supported the role of PDNVs in the modulation of first-line innate responses when plants are attacked by pathogens [11,16-18], by also transferring non-coding RNAs to pathogens $[12,16]$ and in regulating gene expression over long distances [21]. Production of vesicles is increased to contrast biotic stresses during pathogen infection $[18,22,23]$. Plant-derived vesicles were found in xylem wash fluid, but how they cross the plant wall remains unclear [24,25].

The constitutive properties of PDNVs make them suitable for clinical application, including delivery through internalization, low immunogenicity, stability in the gastrointestinal tract and the ability to cross the Blood-Brain Barrier $[10,26,27]$. Some recent studies have been focused on the interaction between nanovesicles and intestinal tissue. For example, nanovesicles from ginger, grapefruit, grape, lemon and broccoli may have a role in prevention of inflammatory bowel disease, by both blocking the damaging factors and improving the expression of the healing factors [10-12,28-31]. Moreover, ginger-derived nanovesicles both induce the expression of detoxifying genes and inhibit ROS accumulation in the liver injured by alcohol [32]. Strawberry- and lemon-derived vesicles exert a potent antioxidant effect preventing oxidative stress in Human Mesenchymal Cells [33,34]. Intraperitoneal administration of honey-derived nanoparticles alleviates inflammation and liver damage in mice with liver injury [35]. Moreover, it has been shown that PDNVs exert anti-cancer effects in melanoma and lung carcinoma-derived cell lines [29,36,37]. Some clinical trials are currently in progress with the purpose to evaluate the ability of PDNVs to either prevent or treat human diseases, e.g., a study is ongoing with the aim to evaluate the effectiveness of PDNVs in reducing insulin resistance (NCT03493984) [38], while another study is investigating the ability of PDNVs in preventing the side effects of chemotherapy (NCT01668849) [39]. They can also be used as drug delivery system in combination with siRNAs and miRNAs [26,40].

A wide panel of artificial nanovesicles are still under investigation, while their use is limited by their low production scale and the need to test each component in vivo before clinical application. PDNVs are excellent candidates as nanodelivery carriers since they are totally natural vesicles, intrinsically made of sustainable and biodegradable materials, and with the potential to be isolated in large amounts [41,42]. Moreover, PDNVs have shown a higher uptake efficiency as compared to artificial nanoparticles, such as liposome formulations [40]. Another plus point for the clinical application of plant nanovesicles is they can be obtained by organic agriculture, which is without pesticides and chemical fertilizers. In fact, our group has demonstrated that human exosomes actively participate in the scavenging activity of unwanted or toxic materials, such as gold nanoparticles [43]. By analogy, plant nanovesicles may be involved in the elimination of toxic materials present in the environment by concentrating the toxics into the PDNVs. Based on the above background, in this study, we first wanted to evaluate the differences between the nanovesicles isolated from organic and conventional fruits in terms of both yield and Total Antioxidant Capacity. A further set of experiments was aimed at measuring the level of the effective bioactive form of the analyzed molecules in plant-derived nanovesicles, by using specific ELISA colorimetric assays. Thereby we characterized the antioxidant content of the nanovesicles isolated from two fruit mixes in terms of Total Antioxidant Capacity and single antioxidants such as Catalase and Superoxide Dismutase 1, Glutathione and Ascorbic Acid. We finally evaluated the resistance of the membranes to both chemical and physical lysis, analyzing the number, size and Total Antioxidant Capacity of the nanovesicles. 


\section{Results}

\subsection{Characterization of Nanovesicles from Organic and Conventional Agriculture}

Organic production is not simply the avoidance of conventional chemical inputs but relies on ecological processes and cycles adapted to local conditions, aiming to maintain biological diversity and produce food in an eco-sustainable way. It is thus conceivable that the farming system (organic or conventional) can influence the characteristics of the crop and consequently the amount and content of isolated vesicles. Thereby, starting from the same amount of fruit extracts, we isolated nanovesicles from four fruits: kiwi (A. chinensis), lemon (C. limon), grapefruit (C. paradisi) and blood orange (C. sinensis 'Blood Orange'), both from organic and conventional agriculture. To investigate the differences between the isolated nanovesicles, we analyzed them through Nanoparticle Tracking Analysis (NTA) to determine their number and size, and through a colorimetric ELISA kit to detect and quantify their Total Antioxidant Capacity. As shown in Figure 1 and Table 1, nanovesicles derived from organic agriculture were many more compared to the conventional ones. In particular, from organic fruits we isolated $22 \%$ (A. chinensis, $p<0.001), 36 \%$ (C. limon $p<0.05), 39 \%$ (C. paradisi, $p<0.05$ ) and $49 \%$ (C. sinensis 'Blood Orange', $p<0.0001$ ) more vesicles compared to conventional fruits. Significant differences were also observed in the size of the nanovesicles: nanovesicles isolated from organic agriculture-derived fruits were smaller compared to vesicles from conventional fruits $(p<0.05)$ (Table 1$)$.

Table 1. Characterization of nanovesicles isolated from organic agriculture-derived and conventional agriculture-derived fruits.

\begin{tabular}{|c|c|c|c|}
\hline Fruit & Type of Agriculture & Number of Nanovesicles & Mean (nm) \\
\hline \multirow[t]{2}{*}{ A. chinensis } & $\begin{array}{c}\text { Conventional } \\
\text { Agriculture }\end{array}$ & $9.0 \times 10^{11} \pm 3.9 \times 10^{10}$ & $166.4 \pm 3.9$ \\
\hline & Organic Agriculture & $1.1 \times 10^{12} \pm 2.7 \times 10^{10}$ & $161.6 \pm 0.6$ \\
\hline \multirow{2}{*}{ C. limon } & $\begin{array}{c}\text { Conventional } \\
\text { Agriculture }\end{array}$ & $9.5 \times 10^{11} \pm 5.7 \times 10^{10}$ & $210.0 \pm 2.5$ \\
\hline & Organic Agriculture & $1.3 \times 10^{12} \pm 2.3 \times 10^{10}$ & $193.5 \pm 2.2$ \\
\hline \multirow{2}{*}{ C. paradisi } & $\begin{array}{c}\text { Conventional } \\
\text { Agriculture }\end{array}$ & $3.6 \times 10^{12} \pm 4.8 \times 10^{10}$ & $198.9 \pm 3.7$ \\
\hline & Organic Agriculture & $5.0 \times 10^{12} \pm 7.8 \times 10^{10}$ & $147.7 \pm 2.4$ \\
\hline \multirow{2}{*}{ C. sinensis } & $\begin{array}{c}\text { Conventional } \\
\text { Agriculture }\end{array}$ & $6.3 \times 10^{11} \pm 2.4 \times 10^{10}$ & $201.7 \pm 5.6$ \\
\hline & Organic Agriculture & $9.4 \times 10^{11} \pm 3.3 \times 10^{10}$ & $178.8 \pm 4.3$ \\
\hline
\end{tabular}

Data are expressed as the mean \pm SE.

To further investigate the differences between the vesicles isolated from organic agriculture fruits and conventional ones, we evaluated the antioxidant content. In Figure 2 are reported the Total Antioxidant Capacities of the various analyzed samples. Total Antioxidant Capacity (TAC) is not only the sum of the antioxidant capacities of individual bioactive compounds but also derived from the synergistic effects between the bioactive compounds, metals and other food constituents [44]. The test used can detect both hydrophilic (i.e., vitamin $\mathrm{C}$ and glutathione) and hydrophobic antioxidants (i.e., Vitamin E). Like the nanovesicle number quantification, the antioxidant content of the PDNVs isolated from the organic fruits were higher compared to the PDNVs from conventional fruits. In detail, the Total Antioxidant Capacities in the organic agriculture-derived nanovesicles were $11 \%$ (A. chinensis, $p<0.0001), 7 \%$ (C. limon, $p<0.05), 21 \%$ (C. paradisi, $p<0.05)$ and $6 \%(C$. sinensis 'Blood Orange', $p<0.001)$ higher than TAC in conventional nanovesicles. 
(a)

A. chinensis

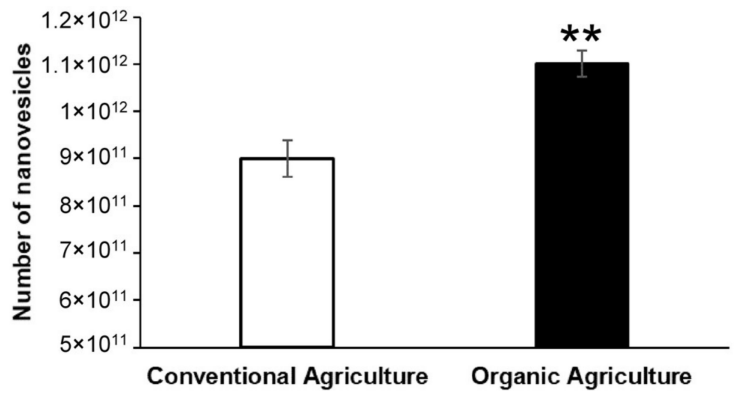

(b)

C. limon

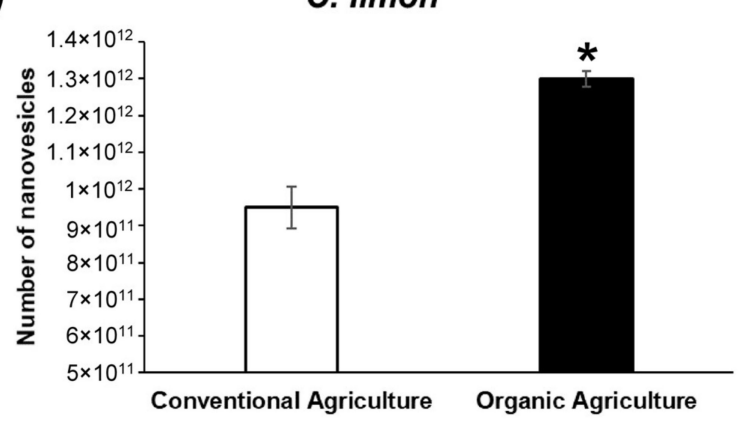

(c)

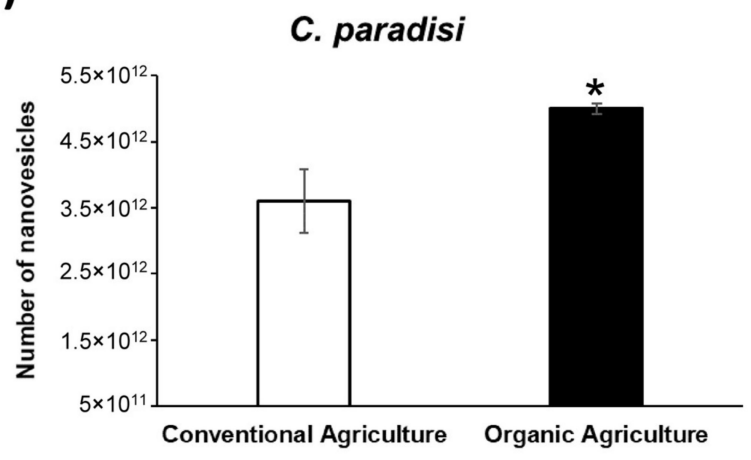

(d)

\section{C. sinensis}

'Blood Orange'

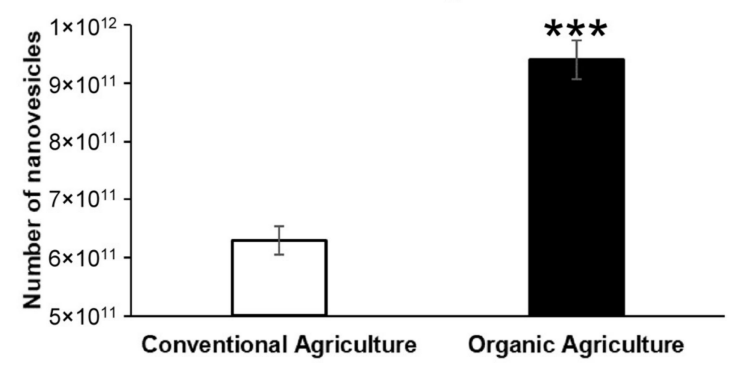

Figure 1. Quantification of conventional and organic agriculture-derived nanovesicles through Nanoparticle Tracking Analysis (NTA): (a) quantification of nanovesicles isolated from kiwi ( $A$. chinensis); (b) quantification of nanovesicles isolated from lemon (C. limon); (c) quantification of nanovesicles isolated from grapefruit (C. paradisi); (d) quantification of nanovesicles isolated from blood orange (C. sinensis 'Blood Orange'). Data are expressed as the mean \pm SE. *: $p<0.05$; **: $p<0.001 ;{ }^{* * *}: p<0.0001$. 
(a)

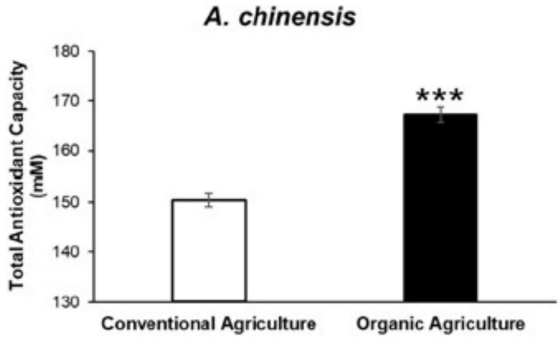

(b)

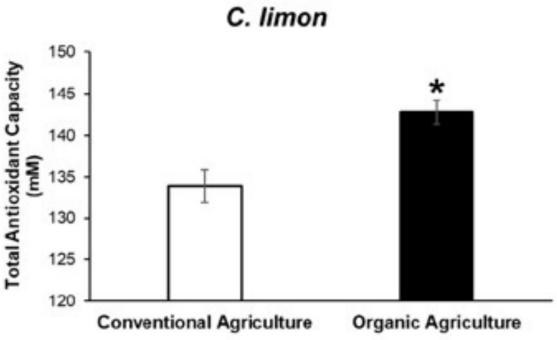

(c)

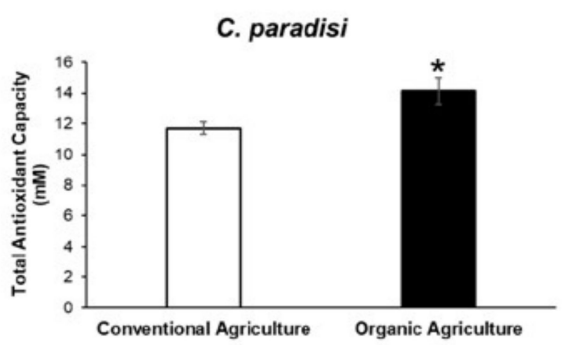

(d)

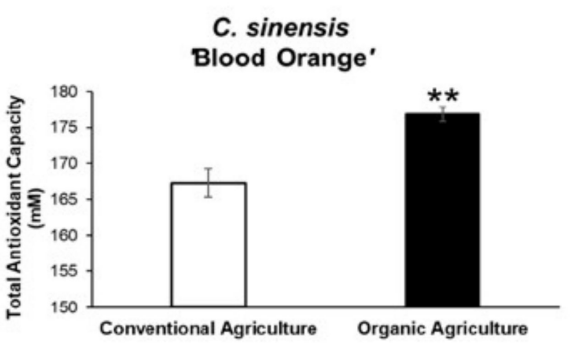

Figure 2. Determination of the Total Antioxidant Capacity (TAC) of organic and conventional agriculture-derived nanovesicles: (a) Total Antioxidant Capacity of the nanovesicles isolated from kiwi (A. chinensis); (b) Total Antioxidant Capacity of the nanovesicles isolated from lemon (C. limon); (c) Total Antioxidant Capacity of the nanovesicles isolated from grapefruit (C. paradisi); (d) Total Antioxidant Capacity of the nanovesicles isolated from blood orange (C. sinensis 'Blood Orange'). Data are expressed as the mean \pm SE. $*: p<0.05 ;{ }^{* *}: p<0.001 ;{ }^{* * *}: p<0.0001$.

\subsection{Characterization and Antioxidant Content of Nanovesicles Isolated from Two Different Fruit Mixes}

After determining the differences between the nanovesicles from organic and conventional fruit, we decided to study the content of PDNVs isolated from organic fruit mixes. Starting from the evidence that the antioxidant activity is increased when a combination of fruits and/or plants is used [45-47], it is plausible that the antioxidant activity is also increased in the isolated nanovesicles. For this purpose, we prepared two different fruit mixes: Mix 1 was composed of kiwi (A. chinensis), orange (C. sinensis), blood orange ( $C$. sinensis 'Blood Orange'), lemon (C. limon) and papaya (C. papaya L.); and Mix 2 of bergamot (C. bergamia), grapefruit (C. paradisi), orange (C. sinensis), blood orange (C. sinensis 'Blood Orange'), lemon (C. limon) and mango (M. indica). First of all, we isolated nanovesicles 
from individual fruit extracts and analyzed them through NTA (Figure 3). All the samples analyzed have the typical sizes of extracellular vesicles: A. chinensis $161 \pm 0.6 \mathrm{~nm}$ (Figure 3a), C. papaya $172.8 \pm 12.8 \mathrm{~nm}$ (Figure 3b), C. bergamia $190.2 \pm 7.2 \mathrm{~nm}$ (Figure 3c), C. limon $194 \pm 3.1 \mathrm{~nm}$ (Figure 3d), C. paradisi $141.7 \pm 5.9 \mathrm{~nm}$ (Figure 3e), C. sinensis $154 \pm 6.3 \mathrm{~nm}$ (Figure 3f), C. sinensis 'Blood orange' $125.3 \pm 2.7$ (Figure 3g) and M. indica $285 \pm 11.5 \mathrm{~nm}$ (Figure $3 \mathrm{~h}$ ).

(a)

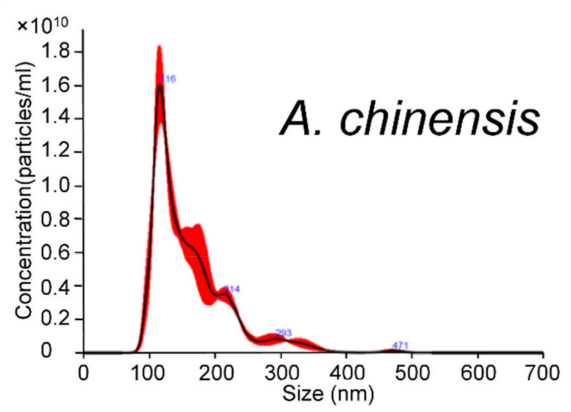

(c)

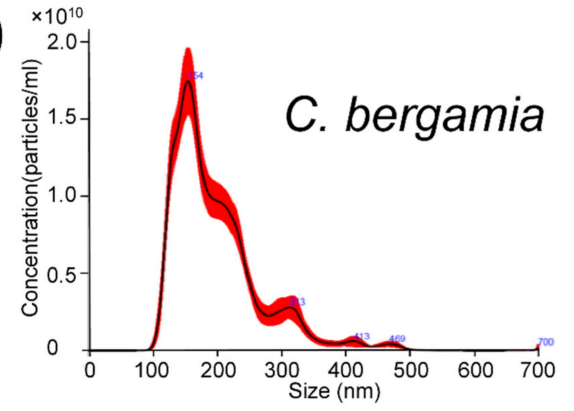

(e)

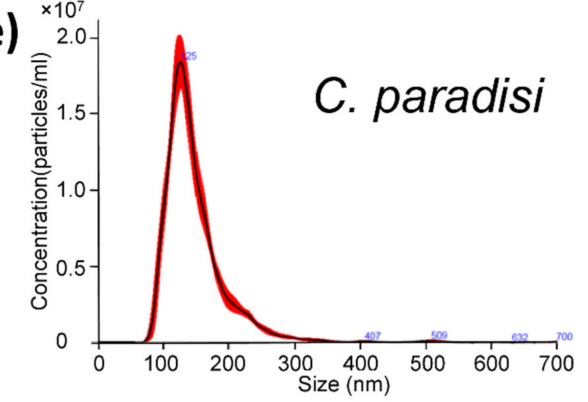

(g)

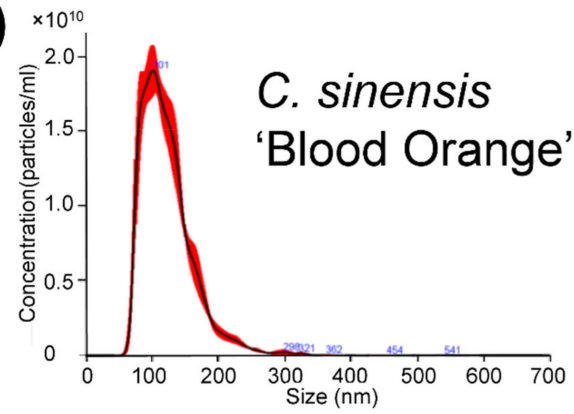

(b)

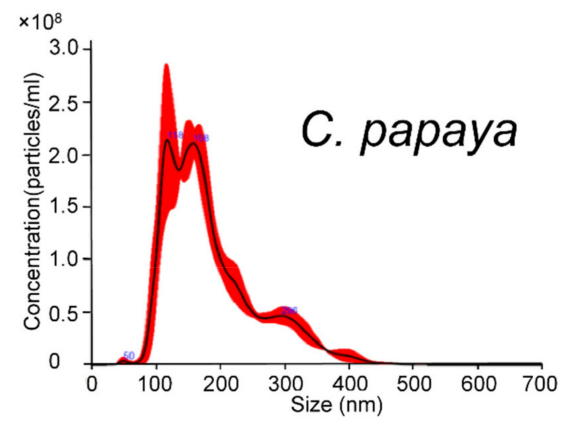

(d)

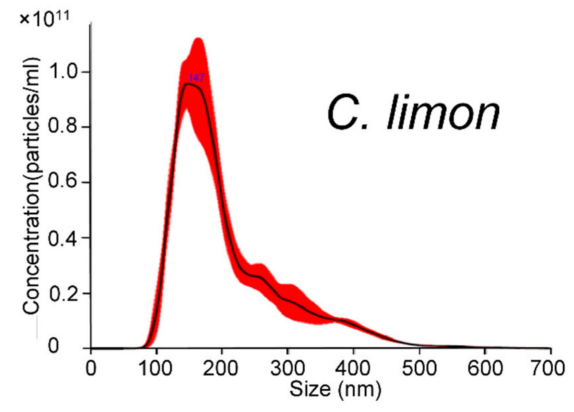

(f)

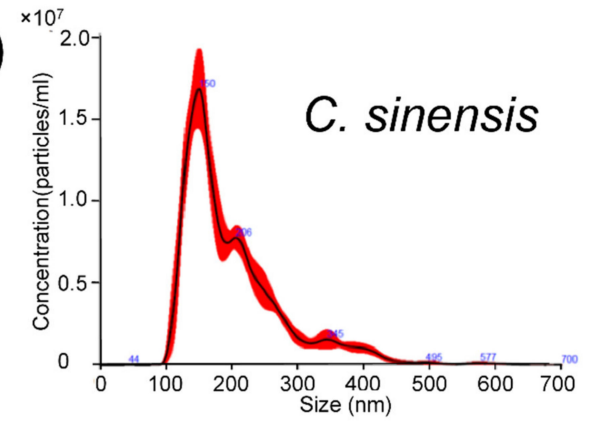

(h)

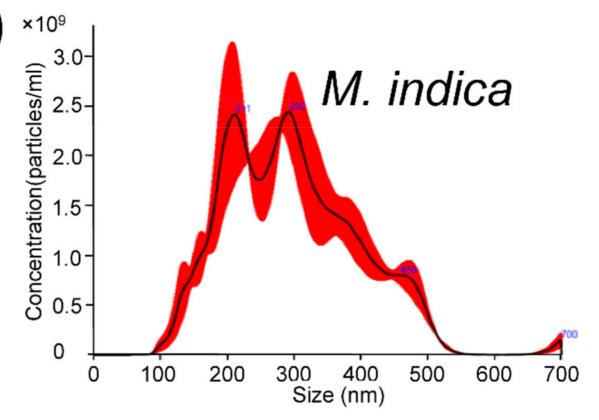

Figure 3. Distribution of organic agriculture-derived nanovesicles analyzed through NTA: (a) distribution of the nanovesicles isolated from kiwi (A. chinensis); (b) distribution of the nanovesicles isolated from papaya (C. papaya); (c) distribution of the nanovesicles isolated from bergamot (C. bergamia); (d) distribution of the nanovesicles isolated from lemon (C. limon); (e) distribution of the nanovesicles isolated from grapefruit (C. paradisi); (f) distribution of the nanovesicles isolated from orange (C. sinensis); (g) distribution of the nanovesicles isolated from blood orange (C. sinensis 'Blood Orange'); (h) distribution of the nanovesicles isolated from mango (M. indica). 
Then we analyzed the distribution of the nanovesicles isolated from fruit mixes through Nanoparticle Tracking Analysis and the results are reported in Figure 4a,b. Although deriving from different fruits, the isolated nanovesicles have a fairly homogeneous distribution, with no signs of damage even after the ultracentrifugation rounds. In fact, the nanovesicles' sizes for Mix 1 and Mix 2 were, respectively, $165.9 \pm 8.9 \mathrm{~nm}$ and $176.3 \pm 10.8 \mathrm{~nm}$, confirming the presence of the vesicles within the typical range of nanovesicles. After the quality assessment, in terms of both number and size of the nanovesicles through NTA, we quantified the antioxidant content of a defined number of nanovesicles though ELISA assay. We first measured the Total Antioxidant Capacity (TAC), which includes the cumulative and synergistic action of all antioxidants present in the analyzed samples, thus providing a measure of the entire antioxidant content in our nanovesicle preparation, rather than a mere sum of each single, measurable antioxidant. The results showed that the nanovesicle preparation derived from both fruit mixes contained very high levels of TAC: respectively, $1.74 \pm 0.13 \mathrm{M}$ for Mix 1 and $1.78 \pm 0.15 \mathrm{M}$ for Mix 2. Thus, we stepped ahead by measuring the single antioxidants within our nanovesicle preparations. Within the same preparations, both enzymatic antioxidants, such as Catalase and Superoxide dismutase 1 (SOD-1), and non-enzymatic antioxidants, such as Glutathione (GSH) and Ascorbic Acid, were measurable (Figure 4). Ascorbic Acid in plants plays predominantly a protective role by scavenging reactive oxygen species, but it is also an important cofactor for several enzymes involved in regulating photosynthesis, hormone biosynthesis and regenerating other antioxidants [48-50]. We were able to measure virtually equal amounts of Ascorbic Acid in both mixes: $3.23 \pm 0.07 \mu \mathrm{g}$ for Mix 1-derived nanovesicles and $4.61 \pm 0.02 \mu \mathrm{g}$ for Mix 2-derived nanovesicles, respectively (Figure 4d). Catalase in plants is a crucial enzyme for survival under metal stress, besides having a fundamental role in the scavenging of reactive oxygen species [51,52]. In nanovesicles isolated from both mixes, we determined high levels of Catalase activity: respectively, $1713 \pm 30 \mathrm{mU} / \mathrm{mL}$ and $920 \pm 45 \mathrm{mU} / \mathrm{mL}$ for Mix 1 and Mix 2 (1 unit of Catalase activity corresponds to amount of Catalase that decomposes $1.0 \mu \mathrm{mol}$ of $\mathrm{H}_{2} \mathrm{O}_{2}$ per minute at $\mathrm{pH} 4.5$ at $25^{\circ} \mathrm{C}$ ) (Figure 4e). Glutathione is considered a strong non-enzymatic antioxidant, which participates both directly and indirectly in the detoxification of ROS, and as cofactor of several biochemical reactions, including signal transduction $[53,54]$. We found equal Glutathione concentrations in the two mixes ( $549 \pm 15 \mu \mathrm{M}$ for Mix 1 and $551.9 \pm 12 \mu \mathrm{M}$ for Mix 2). Finally, we investigated Superoxide Dismutase 1 activity in our nanovesicles' preparations. Superoxide Dismutase is known as the first line of defense against oxidative stresses in plants and plays pivotal role in scavenging the reactive oxygen species generated from both metabolic processes and under abiotic stresses [55-57]. Again, the two nanovesicle mixes showed highly comparable amounts of SOD-1 ( $557 \pm 13 \mathrm{U} / \mathrm{mL}$ for Mix 1 and $527 \pm 14 \mathrm{U} / \mathrm{mL}$ for Mix 2). This set of results showed that nanovesicles purified from either different single fruits or mixes of fruit extracts both exert a very potent Total Antioxidant Capacity (TAC) and contain single antioxidants that are clearly measurable as single bioactives. 
(a)

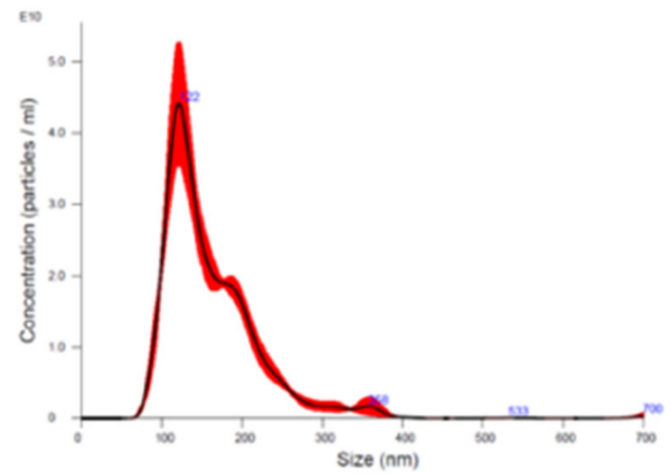

Mix 1 (b)

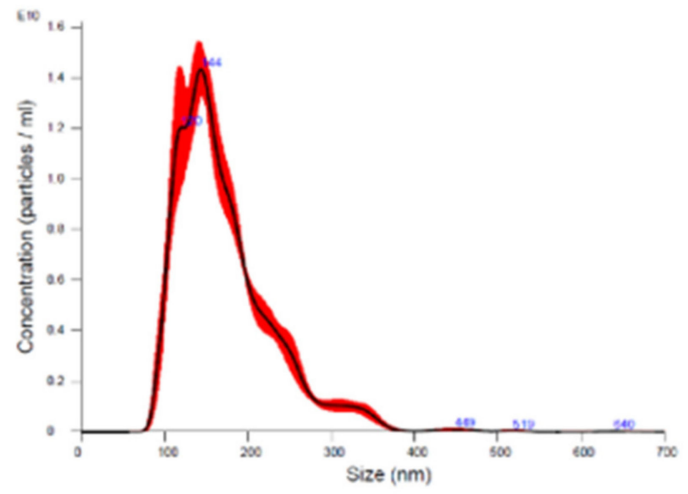

Mix 2

(c)

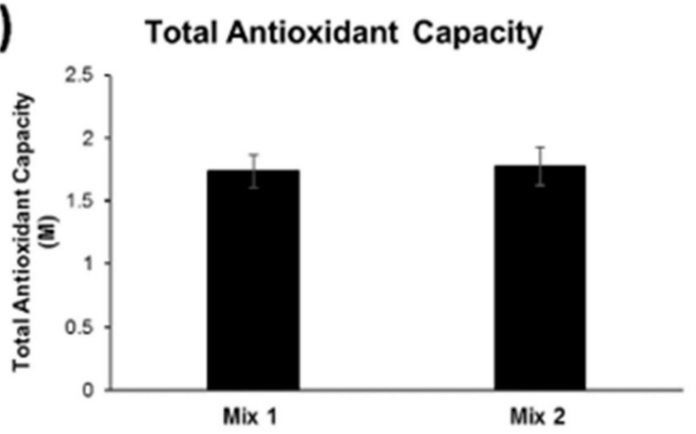

(d)

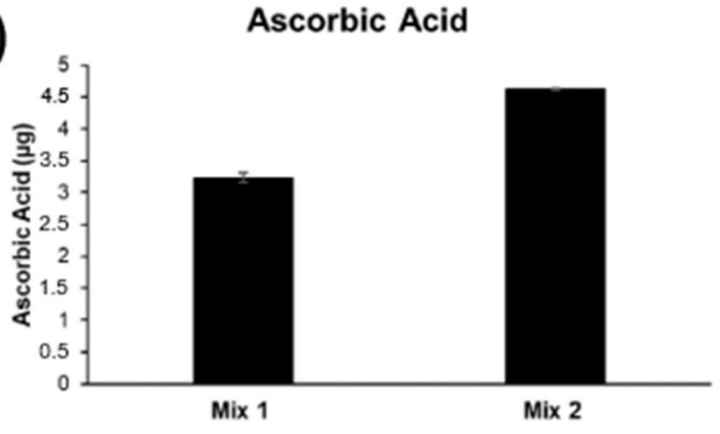

(f)

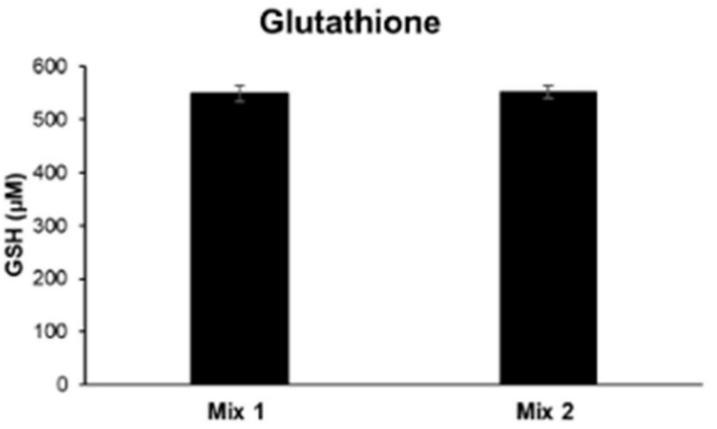

(e)

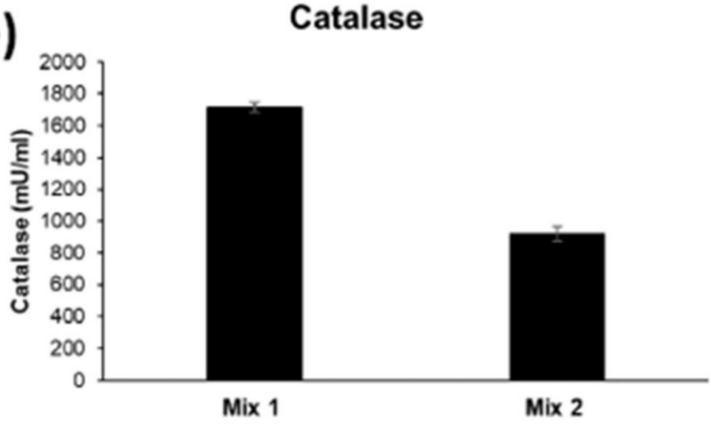

(g)

Superoxide dismutase 1

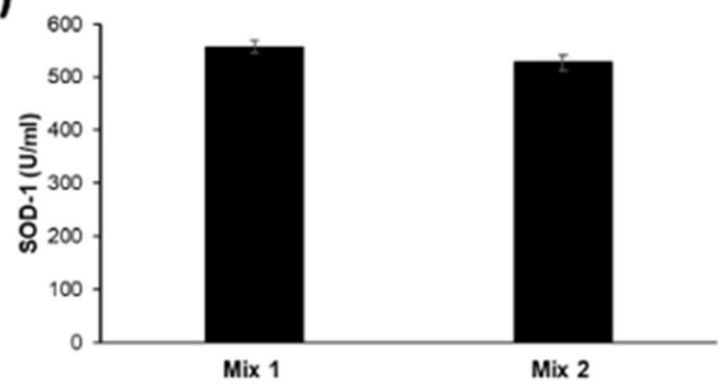

Figure 4. Characterization of antioxidants in organic-derived nanovesicles: (a) distribution of the nanovesicles isolated from Mix 1 analyzed through NTA; (b) distribution of the nanovesicles isolated from Mix 2 analyzed through NTA; (c) quantification of the Total Antioxidant Capacity in nanovesicles isolated from Mix 1 and Mix 2; (d) quantification of the Ascorbic Acid in nanovesicles isolated from Mix 1 and Mix 2; (e) quantification of the Catalase activity in nanovesicles isolated from Mix 1 and Mix 2; (f) quantification of the Glutathione in nanovesicles isolated from Mix 1 and Mix 2; (g) quantification of the Superoxide Dismutase 1 activity in nanovesicles isolated from Mix 1 and Mix 2. Data are expressed as the mean \pm SE. 


\subsection{Nanovesicles Are Resistant to Chemical Lysis}

It is well known that plant-derived nanovesicles are highly stable at different conditions and resistant to digestion by gastric pepsin solution, pancreatic enzymes and bile [40]. For the purpose of evaluating the resistance of the nanovesicles to lytic substances, we exposed our nanovesicle preparations to either chemical lysis, through a lysis buffer commonly used for protein extraction or physical lysis, or through an ultrasonic bath sonicator. Following the two alternative treatments, we compared the number, mean size and Total Antioxidant Capacity in either the lysed or non-lysed nanovesicles. As reported in Figure 5, the results obtained by NTA did not show statistically significant differences between all the analyzed conditions. In detail, for Mix 1, the number of lysed nanovesicles was $1.1 \times 10^{11} \pm 6.45 \times 10^{9}$ (chemical lysis) and $1.04 \times 10^{11} \pm 3.64 \times 10^{9}$ (physical lysis), as compared to the non-lysed initial vesicles $\left(1.02 \times 10^{11} \pm 4.72 \times 10^{9}\right)(\mathrm{ns}: p>0.05)$ (Figure 5a). For Mix 2, the number of nanovesicles that underwent the lytic treatments were $1.33 \times 10^{11} \pm 3.66 \times 10^{9}$ after chemical lysis, and $1.34 \times 10^{11} \pm 1.29 \times 10^{9}$ after physical lysis as compared to non-lysed nanovesicles $\left(1.42 \times 10^{11} \pm 5.62 \times 10^{9}\right)$ (ns: $p>0.05$ ).

Through NTA analysis, we also determined the mean size of the lysed and non-lysed nanovesicles. Comparably to the number, we found no significant differences between the lysed and non-lysed samples for the isolated nanovesicles from both fruit mixes (Mix 1: non-lysed nanovesicles $151.2 \pm 4.6 \mathrm{~nm}$; after chemical lysis $145.1 \pm 2.4 \mathrm{~nm}$; and after physical lysis $154.5 \pm 4.7 \mathrm{~nm}$; ns: $p>0.05$. Mix 2: non-lysed nanovesicles $188.6 \pm 4.5 \mathrm{~nm}$; after chemical lysis $179.9 \pm 5.0 \mathrm{~nm}$; and after physical lysis $185.4 \pm 5.1 \mathrm{~nm} ; \mathrm{ns}: p>0.05$ ) (Figure $5 c, d$ ). Taking together, these data showed clearly that our fruit-derived nanovesicles were fully resistant to both chemical and physical lysis, the number and size of the treated nanovesicles remaining virtually identical to the untreated samples, in turn suggesting the high level of resistance to degradative stimuli of the plant-derived nanovesicles. To complete this set of experiments, in the same samples we compared the Total Antioxidant Capacity between nanovesicles undergoing, or not, lytic treatments. Similarly to the results obtained by analyzing the number and size, the nanovesicles showed a highly comparable TAC concentration, independent of the treatment used: for Mix $124.7 \pm 1.0 \mathrm{mM}$ without treatment, $25.1 \pm 0.1 \mathrm{mM}$ following CHAPS buffer treatment and $23.7 \pm 0.6 \mathrm{mM}$ after lysis in an ultrasonic bath sonicator (ns: $p>0.05$ ) (Figure 5e); we obtained comparable results with Mix 2 as well $(26.9 \pm 0.04 \mathrm{mM}$ in PBS, $27.3 \pm 0.2 \mathrm{mM}$ after chemical lysis and $26.7 \pm 0.1 \mathrm{mM}$ after physical lysis) (ns: $p>0.05$ ) (Figure $5 \mathrm{f}$ ).

This set of results showed that lytic treatments did not affect the integrity of the plant-derived nanovesicles, not only in terms of number and size but in their antioxidant content as well. 
(a)

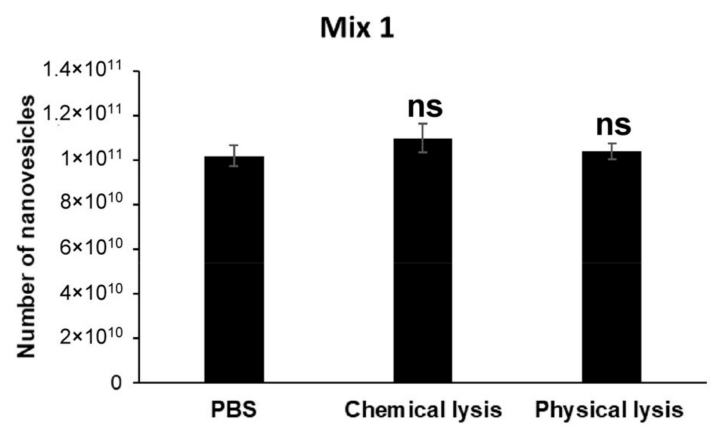

(c)

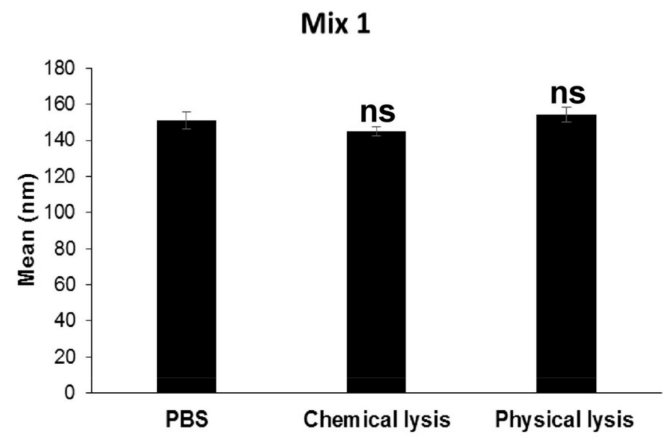

(e)

Mix 1

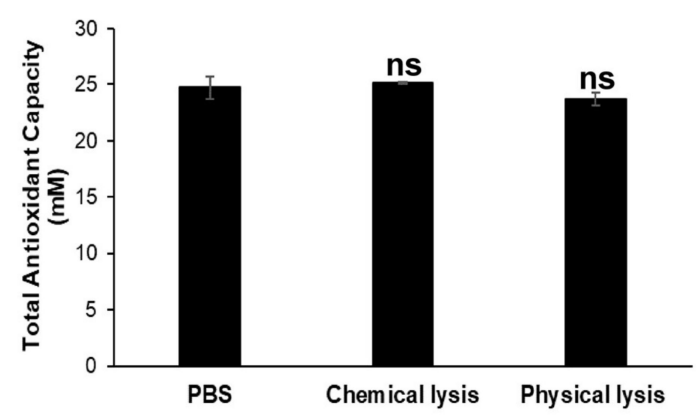

(b)

Mix 2

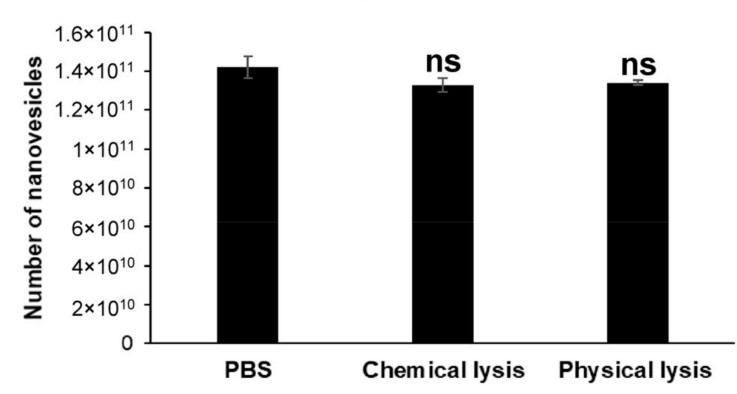

(d)

Mix 2

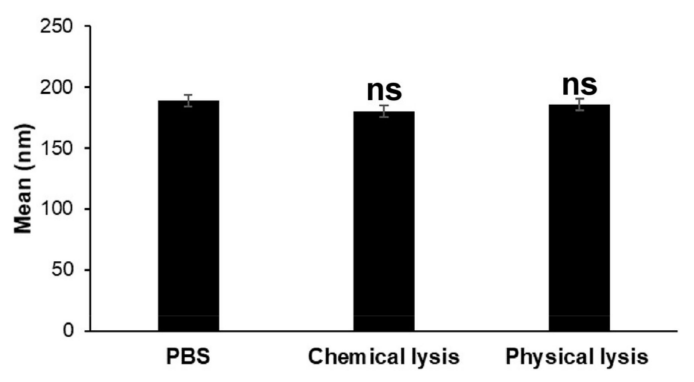

(f)

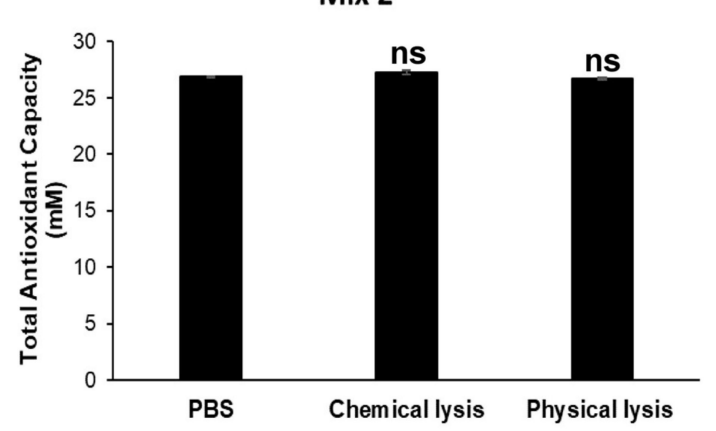

Figure 5. Evaluation of nanovesicle resistance to lysis: (a) comparison of the number of nanovesicles isolated from Mix 1 in PBS (not lysed), after chemical lysis (CHAPS buffer) and physical lysis (ultrasonic bath sonicator), analyzed through NTA; (b) comparison of the number of nanovesicles isolated from Mix 2 in PBS (not lysed), after chemical lysis (CHAPS buffer) and physical lysis (ultrasonic bath sonicator), analyzed through NTA; (c) comparison of the mean size of the nanovesicles isolated from Mix 1 in PBS (not lysed), after chemical lysis buffer (CHAPS buffer) and physical lysis (ultrasonic bath sonicator), analyzed through NTA; (d) comparison of the mean size of the nanovesicles isolated from Mix 2 in PBS (not lysed), after chemical lysis buffer (CHAPS buffer) and physical lysis (ultrasonic bath sonicator), analyzed through NTA; (e) comparison of the Total Antioxidant Capacity in nanovesicles isolated from Mix 1 in PBS (not lysed), after chemical lysis (CHAPS buffer) and physical lysis (ultrasonic bath sonicator), analyzed through a colorimetric ELISA kit; (f) comparison of the Total Antioxidant Capacity in nanovesicles isolated from Mix 2 in PBS (not lysed), after chemical lysis (CHAPS buffer) and physical lysis (ultrasonic bath sonicator), analyzed through a colorimetric ELISA kit. Data are expressed as the mean \pm SE. ns: $p>0.05$. 


\section{Discussion}

The correlation between dietary consumption of antioxidants from fruits and vegetables and the increase in antioxidant levels in treated subjects have been widely studied [58-60]. Moreover, we also know that a diet mostly based on fruits and vegetables, or their derivates, is associated with a reduced risk of diabetes, cardiovascular diseases, age-related diseases, and cancer [60-69]. On the other hand, the majority of suppliers derive antioxidants by either chemical extraction or synthetic phytochemical procedures, which do not show the same effectiveness as plant derivates. From our data and the data of other authors, it appears conceivable that the different bioactives contained in plants may be complexed and, in a way, protected from oxidation and degradation, thus rendering them more powerful than single bioactives. Another crucial issue is the level of bioavailability that is indeed low or very low as far as the standard suppliers are concerned [5,42]. Nanovesicles can be isolated from different fruits and vegetables $[41,70,71]$ and they could well overcome the limitations of current bioproducts. Lastly, plants represent green, sustainable and renewable sources of nanovesicles [72,73], and this can ensure a constant and never-ending production, in turn providing bioproducts that are immediately available at low dosages, stable and more effective than the current products, and therefore more suitable for clinical use and the market.

In this study, we first obtained nanovesicles isolated from organic agriculture-derived fruits, in turn evaluating the potential differences between the nanovesicles isolated from fruits deriving from either organic or conventional agriculture. The fundamental difference between these two farming systems is the total absence of synthetic pesticides in organic agriculture, in order to limit consumers' exposure to pesticide residues in fruits and vegetables [74,75]. A quantitative analysis by NTA has shown that at an equal volume of fruit juice we obtained more nanovesicles from the juice of an organic agriculture source as compared to the juice from intensive agriculture. Moreover, nanovesicles from the juice of organic agriculture showed higher Total Antioxidant Capacity as compared to conventional agriculture-derived nanovesicles. These data appear highly reasonable and conceivable inasmuch as these different agriculture practices may have a strong impact on a plant's metabolism, leading to differences in crop composition, also reflecting on the fruit and vegetable harvesting and therefore on the yield of the internal components of the plants, including nanovesicles $[75,76]$. Moreover, natural fertilizers in organic farming affect the profile of the secondary metabolites in plant tissues by changing the protein expression [76-79].

In this study, we also measured the antioxidant content in nanovesicles isolated from either single fruits or a mix fruit extracts. After a careful characterization of both the distribution and size of the nanovesicles derived from the two sets of fruit, we first measured the Total Antioxidant Capacity (TAC) (i.e., the amount of free radicals scavenged by a test solution), which is typically used for antioxidant determination in biological samples [80-83]. Actually, TAC depends on the synergy, in terms of redox interaction, between the different bioactives present in the various foods $[84,85]$. We thus decided to evaluate the levels of single antioxidants in nanovesicles isolated form different fruits. We knew that some constitutive bioactives of plants, such as Catalase, Glutathione (GSH), Superoxide Dismutase 1 (SOD 1) and Ascorbic Acid, are all fully able to scavenge $\mathrm{H}_{2} \mathrm{O}_{2}$ and reactive oxygen species (ROS), generated by a series of cellular processes, including mitochondrial electron transport, $\beta$-oxidation of the fatty acids and photorespiratory oxidation $[49,53-56,86,87]$. Moreover, the abovementioned antioxidants play a crucial role in plant defense, aging and senescence [86], plant tolerance to abiotic stresses and toxic metal stress [53]. For instance, GSH scavenges free radicals and other reactive oxygen species directly or indirectly through enzymatic reactions [54,87]. Based on this background, we were able to detect and quantify several antioxidants in nanovesicles isolated from organic fruit mixes, including Catalase, GSH, SOD 1 and Ascorbic Acid. The evidence that the various antioxidants are contained and fairly measurable in the fruit's nanovesicles suggests that when ingested within nanovesicles, the antioxidants may remain stably 
bioavailable, being protected from quick oxidation but also from lysis and enzymatic digestion in gastric and intestinal solutions $[9,40]$. This suggests the potential use of vegetables-derived derived nanovesicles as a therapeutic agent in oxidative stress- and agerelated diseases $[52,57]$. The results of this study confirm that plant-derived nanovesicles represent an excellent nanodelivery system for constitutively expressed natural compounds, thanks to their sizes, safety, biocompatibility, and stability [42,88]. For example, grapefruit nanovesicles are highly stable in solutions mimicking gastric and intestinal conditions [40]. In fact, our results have also shown that both chemical and physical lysis did not affect the nanovesicles' distribution and antioxidant content, further supporting the high potential of fruit and vegetable-derived nanovesicles for therapeutic use.

All in all, the results of our study provide for the first time a series of critical evidence on the potential use of plant-derived nanovesicles in human beings' daily supplementation. First, they can be obtained and analyzed in both a quantitative and qualitative way. There are substantial, both quantitative and qualitative, differences between the nanovesicles obtained from fruits deriving from organic agriculture as compared to those obtained from conventional agriculture. The bioactives contained in plant-derived nanovesicles are stable and complexed between them within the nanovesicles, thus allowing a more powerful and combined antioxidant effect. The bioactives are fairly stable within the nanovesicles, thus allowing a long-standing bioavailability.

\section{Materials and Methods}

\subsection{Fruit Material}

Kiwi (A. chinensis), orange (C. sinensis), blood orange (C. sinensis 'Blood Orange'), lemon (C. limon), papaya (C. papaya L.) and mango (M. indica) were purchased from several farms with organic farming certification and from conventional farms, under the same conditions (season, climate, area of cultivation and degree of ripeness). The fruits were washed with water and bicarbonate, peeled, and extracted with a fruit juice extractor. Fruit juices were stored at $-80^{\circ} \mathrm{C}$.

\subsection{Nanovesicles Isolation}

Fruit juices were centrifuged at $500 \times g \times 10 \mathrm{~min}$; the supernatants were filtered with $100 \mu \mathrm{m}$ filters and serially centrifugated at $2000 \times g$ for $20 \mathrm{~min}$ to eliminate cell debris and then at $15,000 \times g$ for $30 \mathrm{~min}$ to eliminate the fraction enriched in microvesicles. The supernatants were subsequently ultracentrifuged in a Sorvall WX Ultracentrifuge Series (Thermo Fisher Scientific) at 110,000 $\times g$ for $1 \mathrm{~h} 30 \mathrm{~min}$ to collect the nanovesicles. The pellet was resuspended in an appropriate buffer for downstream analyses.

\subsection{Nanoparticle Tracking Analysis}

Nanoparticle Tracking Analysis (NTA) from Malvern (NanoSight NS300, Worcestershire, UK) was used for the measurement of size distribution and concentration of extracellular vesicle samples in the liquid suspension. Five videos of typically $60 \mathrm{~s}$ duration were taken. Data were analyzed using the NTA 3.0 software (Malvern Instruments), which was optimized to first identify and then track each particle on a frame-by-frame basis. The Brownian motion of each particle was tracked using the Stokes-Einstein equation: $\mathrm{D}^{\circ}=\mathrm{kT} / 6 \pi \eta \mathrm{r}$, where $\mathrm{D}^{\circ}$ is the diffusion coefficient, $\mathrm{kT} / 6 \pi \eta \mathrm{r}=\mathrm{f} 0$ is the frictional coefficient of the particle, for the special case of a spherical particle of radius $r$ moving at a uniform velocity in a continuous fluid of viscosity $\eta, \mathrm{k}$ is Boltzmann's constant, and T is the absolute temperature.

\subsection{Total Antioxidant Power Assay (PAO Test Kit)}

Detection and quantification of Total Antioxidant Capacity were performed in nanovesicles using a colorimetric assay: PAO Test kit for Total Antioxidant Capacity (JaICA, Shizuoka, Japan). The assay can detect not only hydrophilic antioxidants, such as Vitamin $\mathrm{C}$ and glutathione, but can also detect hydrophobic antioxidants, such as Vitamin E. 
The determination of the antioxidant power was carried out using a reduction of cupric ion $\left(\mathrm{Cu}^{++}\right.$to $\left.\mathrm{Cu}^{+}\right)$. Briefly, samples were incubated for $3 \mathrm{~min}$ at room temperature with a $\mathrm{Cu}^{++}$solution, and the $\mathrm{Cu}^{++}$was reduced by antioxidants to form $\mathrm{Cu}^{+}$that reacts with a chromatic solution (bathocuproine), and can be detected by absorbance at a wavelength of 480 to $490 \mathrm{~nm}$. Antioxidant capacity can be calculated from the $\mathrm{Cu}^{+}$formed. Absorbance was recorded at $490 \mathrm{~nm}$.

\subsection{Ascorbic Acid Assay}

Detection and quantification of Ascorbic Acid in nanovesicles were performed using a fluorometric Ascorbic Acid Assay Kit (Sigma-Aldrich, St. Louis, MO, USA). Samples were diluted in ascorbic acid buffer in a 96-well plate and subsequently to each well was added a catalyst and then reaction mix (the reaction mix is composed of an ascorbic acid buffer, ascorbic acid probe and ascorbic acid enzyme mix). After $5 \mathrm{~min}$ of incubation, fluorescence was read in a microplate reader at $\mathrm{Ex} / \mathrm{Em}=535 / 587 \mathrm{~nm}$.

\subsection{Catalase Activity Assay}

For the Catalase Activity Assay (Abcam, Cambridge, UK), a fluorometric kit was used for detection and quantification of the Catalase activity in fruit-derived nanovesicles. Briefly, samples resuspended in PBS were loaded in a 96-well plate; a stop solution was added in the control samples and incubated for $5 \mathrm{~min}$ at $25^{\circ} \mathrm{C}$ to inhibit the Catalase activity. Catalase reaction mix (with $\mathrm{H}_{2} \mathrm{O}_{2}$ ) was added to both the control and high control samples for $30 \mathrm{~min}$ at $25^{\circ} \mathrm{C}$. The reaction in the high control samples and standard samples was stopped with the stop solution, the developer was added to all wells and after $10 \mathrm{~min}$ the fluorescence was read at Ex/Em $=535 / 587 \mathrm{~nm}$ on a microplate reader (Promega, Madison, WI, USA). Data were analyzed using the manufacturer's instructions. One unit of Catalase corresponds to the amount of Catalase that will decompose $1 \mu \mathrm{mol}$ of $\mathrm{H}_{2} \mathrm{O}_{2}$ per minute at $\mathrm{pH} 4.5$ at $25^{\circ} \mathrm{C}$.

\subsection{Reduced Glutathione (GSH) Detection and Quantification Assay}

The Glutathione Colorimetric Detection Kit (Thermo Fisher, Waltham, MA, USA), a colorimetric assay, was used for detection and quantification of reduced glutathione (GSH) levels in plasma preparations. Detection reagent and reaction mixture (NADPH and glutathione reductase) were added to samples and after $20 \mathrm{~min}$ of incubation at room temperature, the optical densities were recorded at $405 \mathrm{~nm}$.

\subsection{Superoxide Dismutase (SOD) Activity Assay}

The Superoxide Dismutase Activity kit (Thermo Fisher), a colorimetric assay, was used for detection and quantification of the superoxide dismutase activity nanovesicle preparations. Samples were incubated for $20 \mathrm{~min}$ at room temperature after the addition of the sample and substrate and chromogenic detection reagent. The optical densities were recorded at $450 \mathrm{~nm}$.

\subsection{Nanovesicles Lysis}

Nanovesicles were isolated from fruit through the abovementioned protocol. Then, they were counted by NTA and $10^{11}$ nanovesicles were resuspended in CHAPS buffer (Tris $10 \mathrm{mM} \mathrm{pH} 7.4, \mathrm{MgCl}_{2} 1 \mathrm{mM}$, ethyleneglycoltetraacetic acid (EGTA) $1 \mathrm{mM}, \mathrm{CHAPS} 0.5 \%$, glycerol 10\%, phenylmethylsulfonyl fluoride (PMSF) $1 \mathrm{mM}$, leupeptin $1 \mu \mathrm{g} / \mathrm{mL}$, pepstatin A $1 \mu \mathrm{g} / \mathrm{mL}$, aprotinin $1 \mu \mathrm{g} / \mathrm{mL}$ and PMSF $1 \mathrm{mM}$ ).

For physical lysis, $10^{11}$ nanovesicles were sonicated in an ultrasonic bath sonicator at the maximum frequency $(50 \mathrm{kHz})$ for two minutes.

Sample were analyzed through NTA (Malvern, Worcestershire, UK) to evaluate the number and size, and through a colorimetric ELISA kit to quantify the Total Antioxidant Capacity (JaICA, Japan). 


\subsection{Statistical Analysis}

Results are reported as the means \pm standard error (SE), and calculations were done using GraphPad Prism software (San Diego, CA, USA). An unpaired $t$-test (Student's $t$-test) was applied to analyze the results. Statistical significance was set at $p<0.05$.

Author Contributions: Conceptualization, M.L.; data curation, R.D.R. and D.M.; formal analysis, R.D.R. and D.M.; investigation, R.D.R. and D.M.; methodology, R.D.R. and D.M.; project administration, M.L. and S.F.; resources, M.L. and S.F.; supervision, S.F.; validation, R.D.R.; visualization, R.D.R.; writing-original draft, R.D.R.; writing-review and editing, R.D.R. and S.F. All authors have read and agreed to the published version of the manuscript.

Funding: This work was supported by a grant from the Ministry of Health, Italy.

Data Availability Statement: The data presented in this study are available on request from the corresponding author.

Conflicts of Interest: The authors declare no conflict of interest.

\section{References}

1. Milner, J.A. Molecular targets for bioactive food components. J. Nutr. 2004, 134, 2492S-2498S. [CrossRef]

2. Amagase, H.; Petesch, B.L.; Matsuura, H.; Kasuga, S.; Itakura, Y. Intake of garlic and its bioactive components. J. Nutr. 2001, 131, 955S-962S. [CrossRef] [PubMed]

3. Percival, S.S.; Bukowski, J.F.; Milner, J. Bioactive food components that enhance gammadelta t cell function may play a role in cancer prevention. J. Nutr. 2008, 138, 1-4. [CrossRef]

4. Khushnud, T.; Mousa, S.A. Potential role of naturally derived polyphenols and their nanotechnology delivery in cancer. Mol. Biotechnol. 2013, 55, 78-86. [CrossRef] [PubMed]

5. Bonifácio, B.V.; da Silva, P.B.; dos Santos Ramos, M.A.; Negri, K.M.S.; Bauab, T.M.; Chorilli, M. Nanotechnology-based drug delivery systems and herbal medicines: A review. Int. J. Nanomed. 2014, 9, 1-15. [CrossRef]

6. Strohl, W.R. The role of natural products in a modern drug discovery program. Drug Discov. Today 2000, 5, 39-41. [CrossRef]

7. Manly, S.P.; Padmanabha, R.; Lowe, S.E. Natural products or not? How to screen for natural products in the emerging HTS paradigm. Methods Mol. Biol. 2002, 190, 153-168. [CrossRef]

8. Munir, J.; Lee, M.; Ryu, S. Exosomes in food: Health benefits and clinical relevance in diseases. Adv. Nutr. 2020, 11, 687-696. [CrossRef]

9. Mu, J.; Zhuang, X.; Wang, Q.; Jiang, H.; Deng, Z.-B.; Wang, B.; Zhang, L.; Kakar, S.; Jun, Y.; Miller, D.; et al. Interspecies communication between plant and mouse gut host cells through edible plant derived exosome-like nanoparticles. Mol. Nutr. Food Res. 2014, 58, 1561-1573. [CrossRef] [PubMed]

10. Wang, B.; Zhuang, X.; Deng, Z.-B.; Jiang, H.; Mu, J.; Wang, Q.; Xiang, X.; Guo, H.; Zhang, L.; Dryden, G.; et al. Targeted drug delivery to intestinal macrophages by bioactive nanovesicles released from grapefruit. Mol. Ther. 2014, 22, 522-534. [CrossRef] [PubMed]

11. Ju, S.; Mu, J.; Dokland, T.; Zhuang, X.; Wang, Q.; Jiang, H.; Xiang, X.; Deng, Z.-B.; Wang, B.; Zhang, L.; et al. Grape exosome-like nanoparticles induce intestinal stem cells and protect mice from dss-induced colitis. Mol. Ther. 2013, 21, 1345-1357. [CrossRef] [PubMed]

12. Zhang, M.; Viennois, E.; Xu, C.; Merlin, D. Plant derived edible nanoparticles as a new therapeutic approach against diseases. Tissue Barriers 2016, 4, e1134415. [CrossRef] [PubMed]

13. An, Q.; Hückelhoven, R.; Kogel, K.-H.; van Bel, A.J.E. Multivesicular bodies participate in a cell wall-associated defence response in barley leaves attacked by the pathogenic powdery mildew fungus. Cell. Microbiol. 2006, 8, 1009-1019. [CrossRef]

14. Rome, S. Biological properties of plant-derived extracellular vesicles. Food Funct. 2019, 10, 529-538. [CrossRef]

15. De la Canal, L.; Pinedo, M. Extracellular vesicles: A missing component in plant cell wall remodeling. J. Exp. Bot. 2018, 69, 4655-4658. [CrossRef] [PubMed]

16. Woith, E.; Fuhrmann, G.; Melzig, M.F. Extracellular vesicles-Connecting kingdoms. Int. J. Mol. Sci. 2019, 20, 5695. [CrossRef]

17. Bleackley, M.R.; Dawson, C.S.; Anderson, M.A. Fungal extracellular vesicles with a focus on proteomic analysis. Proteomics 2019, 19, e1800232. [CrossRef]

18. Regente, M.; Pinedo, M.; San Clemente, H.; Balliau, T.; Jamet, E.; de la Canal, L. Plant extracellular vesicles are incorporated by a fungal pathogen and inhibit its growth. J. Exp. Bot. 2017, 68, 5485-5495. [CrossRef]

19. Chukhchin, D.G.; Bolotova, K.; Sinelnikov, I.; Churilov, D.; Novozhilov, E. Exosomes in the phloem and xylem of woody plants. Planta 2020, 251, 12. [CrossRef] [PubMed]

20. Yu, L.; Sun, J.; Li, L. PtrCel9A6, an endo-1,4- $\beta$-glucanase, is required for cell wall formation during xylem differentiation in populus. Mol. Plant. 2013, 6, 1904-1917. [CrossRef]

21. Baldrich, P.; Rutter, B.D.; Karimi, H.Z.; Podicheti, R.; Meyers, B.C.; Innes, R.W. Plant extracellular vesicles contain diverse small RNA species and are enriched in 10- to 17-nucleotide "tiny" RNAs. Plant Cell 2019, 31, 315-324. [CrossRef] [PubMed] 
22. Rutter, B.D.; Innes, R.W. Extracellular vesicles isolated from the leaf apoplast carry stress-response proteins. Plant Physiol. 2017, 173, 728-741. [CrossRef]

23. Cai, Q.; Qiao, L.; Wang, M.; He, B.; Lin, F.-M.; Palmquist, J.; Huang, S.-D.; Jin, H. Plants send small RNAs in extracellular vesicles to fungal pathogen to silence virulence genes. Science 2018, 360, 1126-1129. [CrossRef]

24. Samuel, M.; Bleackley, M.; Anderson, M.; Mathivanan, S. Extracellular vesicles including exosomes in cross kingdom regulation: A viewpoint from plant-fungal interactions. Front. Plant Sci. 2015, 6, 766. [CrossRef]

25. Park, E.; Nedo, A.; Caplan, J.L.; Dinesh-Kumar, S.P. Plant-microbe interactions: Organelles and the cytoskeleton in action. New Phytol. 2018, 217, 1012-1028. [CrossRef]

26. Yang, C.; Zhang, M.; Merlin, D. Advances in plant-derived edible nanoparticle-based lipid nano-drug delivery systems as therapeutic nanomedicines. J. Mater. Chem. B 2018, 6, 1312-1321. [CrossRef] [PubMed]

27. Wang, X.; Zhang, M.; Flores, S.R.L.; Woloshun, R.R.; Yang, C.; Yin, L.; Xiang, P.; Xu, X.; Garrick, M.D.; Vidyasagar, S.; et al. Oral gavage of ginger nanoparticle-derived lipid vectors carrying Dmt1 SiRNA blunts iron loading in murine hereditary hemochromatosis. Mol. Ther. 2019, 27, 493-506. [CrossRef] [PubMed]

28. Zhang, M.; Viennois, E.; Prasad, M.; Zhang, Y.; Wang, L.; Zhang, Z.; Han, M.K.; Xiao, B.; Xu, C.; Srinivasan, S.; et al. Edible ginger-derived nanoparticles: A novel therapeutic approach for the prevention and treatment of inflammatory bowel disease and colitis-associated cancer. Biomaterials 2016, 101, 321-340. [CrossRef]

29. Raimondo, S.; Naselli, F.; Fontana, S.; Monteleone, F.; Lo Dico, A.; Saieva, L.; Zito, G.; Flugy, A.; Manno, M.; Di Bella, M.A.; et al. Citrus limon-derived nanovesicles inhibit cancer cell proliferation and suppress CML xenograft growth by inducing TRAIL-mediated cell death. Oncotarget 2015, 6, 19514-19527. [CrossRef] [PubMed]

30. Zhang, M.; Merlin, D. Nanoparticle-based oral drug delivery systems targeting the colon for treatment of ulcerative colitis. Inflamm. Bowel Dis. 2018, 24, 1401-1415. [CrossRef]

31. Deng, Z.; Rong, Y.; Teng, Y.; Mu, J.; Zhuang, X.; Tseng, M.; Samykutty, A.; Zhang, L.; Yan, J.; Miller, D.; et al. Broccoli-derived nanoparticle inhibits mouse colitis by activating dendritic cell AMP-activated protein kinase. Mol. Ther. 2017, 25, 1641-1654. [CrossRef]

32. Zhuang, X.; Deng, Z.-B.; Mu, J.; Zhang, L.; Yan, J.; Miller, D.; Feng, W.; McClain, C.J.; Zhang, H.-G. Ginger-derived nanoparticles protect against alcohol-induced liver damage. J. Extracell. Vesicles 2015, 4, 28713. [CrossRef] [PubMed]

33. Perut, F.; Roncuzzi, L.; Avnet, S.; Massa, A.; Zini, N.; Sabbadini, S.; Giampieri, F.; Mezzetti, B.; Baldini, N. Strawberry-derived exosome-like nanoparticles prevent oxidative stress in human mesenchymal stromal cells. Biomolecules 2021, 11, 87. [CrossRef]

34. Baldini, N.; Torreggiani, E.; Roncuzzi, L.; Perut, F.; Zini, N.; Avnet, S. Exosome-like nanovesicles isolated from citrus limon L. Exert Antioxidative Effect. Curr. Pharm. Biotechnol. 2018, 19, 877-885. [CrossRef]

35. Chen, X.; Liu, B.; Li, X.; An, T.T.; Zhou, Y.; Li, G.; Wu-Smart, J.; Alvarez, S.; Naldrett, M.J.; Eudy, J.; et al. Identification of anti-inflammatory vesicle-like nanoparticles in honey. J. Extracell. Vesicles 2021, 10, e12069. [CrossRef]

36. Stanly, C.; Alfieri, M.; Ambrosone, A.; Leone, A.; Fiume, I.; Pocsfalvi, G. Grapefruit-derived micro and nanovesicles show distinct metabolome profiles and anticancer activities in the A375 human melanoma cell line. Cells 2020, 9, 2722. [CrossRef] [PubMed]

37. Cao, M.; Yan, H.; Han, X.; Weng, L.; Wei, Q.; Sun, X.; Lu, W.; Wei, Q.; Ye, J.; Cai, X.; et al. Ginseng-derived nanoparticles alter macrophage polarization to inhibit melanoma growth. J. Immunother. Cancer 2019, 7, 326. [CrossRef]

38. University of Louisville. A Preliminary Clinical Trial Investigating the Ability of Plant. Exosomes to Mitigate Insulin Resistance and Chronic Inflammation in Patients Diagnosed With Polycystic Ovary Syndrome (PCOS); University of Louisville: Louisville, KY, USA, 2021.

39. Redman, R. Preliminary clinical trial investigating the ability of plant. exosomes to abrogate oral mucositis induced by combined chemotherapy and radiation in head and neck cancer patients. J. Investig. Med. 2015, 63, 468, clinicaltrials.gov, 2020.

40. Wang, Q.; Zhuang, X.; Mu, J.; Deng, Z.-B.; Jiang, H.; Zhang, L.; Xiang, X.; Wang, B.; Yan, J.; Miller, D.; et al. Delivery of therapeutic agents by nanoparticles made of grapefruit-derived lipids. Nat. Commun. 2013, 4, 1867. [CrossRef]

41. Akuma, P.; Okagu, O.D.; Udenigwe, C.C. Naturally occurring exosome vesicles as potential delivery vehicle for bioactive compounds. Front. Sustain. Food Syst. 2019, 3, 23. [CrossRef]

42. Di Gioia, S.; Hossain, M.N.; Conese, M. Biological properties and therapeutic effects of plant-derived nanovesicles. Open Med. 2020, 15, 1096-1122. [CrossRef]

43. Logozzi, M.; Mizzoni, D.; Bocca, B.; Di Raimo, R.; Petrucci, F.; Caimi, S.; Alimonti, A.; Falchi, M.; Cappello, F.; Campanella, C.; et al. Human primary macrophages scavenge AuNPs and eliminate it through exosomes. a natural shuttling for nanomaterials. Eur. J. Pharm. Biopharm. 2019, 137, 23-36. [CrossRef]

44. Liu, R.H. Potential synergy of phytochemicals in cancer prevention: Mechanism of action. J. Nutr. 2004, 134, 3479S-3485S. [CrossRef]

45. Heo, H.J.; Kim, Y.J.; Chung, D.; Kim, D.-O. Antioxidant capacities of individual and combined phenolics in a model system. Food Chem. 2007, 104, 87-92. [CrossRef]

46. Makanjuola, S.A.; Enujiugha, V.N.; Omoba, O.S.; Sanni, D.M. Combination of antioxidants from different sources could offer synergistic benefits: A case study of tea and ginger blend. Nat. Prod. Commun. 2015, 10, 1829-1832. [CrossRef]

47. Daramola, B. Preliminary Investigation on antioxidant interactions between bioactive components of solanum anguivi and capsicum annuum. J. Food Sci. Technol. 2018, 55, 3827-3832. [CrossRef] 
48. Gallie, D.R. L-ascorbic acid: A multifunctional molecule supporting plant growth and development. Scientifica 2013, $2013,1-24$. [CrossRef]

49. Paciolla, C.; Fortunato, S.; Dipierro, N.; Paradiso, A.; De Leonardis, S.; Mastropasqua, L.; de Pinto, M.C. Vitamin C in plants: From functions to biofortification. Antioxidants 2019, 8, 519. [CrossRef] [PubMed]

50. Ascorbic Acid in Plant Growth, Development and Stress Tolerance; Hossain, M.A.; Munné-Bosch, S.; Burritt, D.J.; Diaz-Vivancos, P.; Fujita, M.; Lorence, A. (Eds.) Springer International Publishing: Cham, Switzerland, 2017; ISBN 978-3-319-74056-0.

51. Sharma, I.; Ahmad, P. Catalase. In Oxidative Damage to Plants; Elsevier: Berkeley, CA, USA, 2014; pp. 131-148. ISBN 978-0-12799963-0.

52. Nandi, A.; Yan, L.-J.; Jana, C.K.; Das, N. Role of catalase in oxidative stress- and age-associated degenerative diseases. Oxidative Med. Cell. Longev. 2019, 2019, 9613090. [CrossRef] [PubMed]

53. Hasanuzzaman, M.; Nahar, K.; Anee, T.I.; Fujita, M. Glutathione in plants: Biosynthesis and physiological role in environmental stress tolerance. Physiol. Mol. Biol. Plants 2017, 23, 249-268. [CrossRef]

54. Wu, G.; Fang, Y.-Z.; Yang, S.; Lupton, J.R.; Turner, N.D. Glutathione metabolism and its implications for health. J. Nutr. 2004, 134, 489-492. [CrossRef]

55. Berwal, M.; Ram, C. Superoxide dismutase: A stable biochemical marker for abiotic stress tolerance in higher plants. In Abiotic and Biotic Stress in Plants; Bosco de Oliveira, A., Ed.; IntechOpen: London, UK, 2019; ISBN 978-1-78923-811-2.

56. Alscher, R.G. Role of superoxide dismutases (SODs) in controlling oxidative stress in plants. J. Exp. Bot. 2002, 53, 1331-1341 [CrossRef] [PubMed]

57. Johnson, F.; Giulivi, C. Superoxide dismutases and their impact upon human health. Mol. Asp. Med. 2005, 26, 340-352. [CrossRef]

58. Gao, J.; Xu, K.; Liu, H.; Liu, G.; Bai, M.; Peng, C.; Li, T.; Yin, Y. Impact of the gut microbiota on intestinal immunity mediated by tryptophan metabolism. Front. Cell. Infect. Microbiol. 2018, 8, 13. [CrossRef]

59. Rubio, C.A.; Schmidt, P.T. Severe defects in the macrophage barrier to gut microflora in inflammatory bowel disease and colon cancer. Anticancer Res. 2018, 38, 3811-3815. [CrossRef]

60. Logozzi, M.; Di Raimo, R.; Mizzoni, D.; Andreotti, M.; Spada, M.; Macchia, D.; Fais, S. Beneficial effects of fermented papaya preparation $\left(\mathrm{FPP}^{\circledR}\right)$ supplementation on redox balance and aging in a mouse model. Antioxidants 2020, 9, 144. [CrossRef] [PubMed]

61. Liu, Z.; Ren, Z.; Zhang, J.; Chuang, C.-C.; Kandaswamy, E.; Zhou, T.; Zuo, L. Role of ROS and nutritional antioxidants in human diseases. Front. Physiol. 2018, 9, 477. [CrossRef]

62. Ouyang, L.; Luo, Y.; Tian, M.; Zhang, S.-Y.; Lu, R.; Wang, J.-H.; Kasimu, R.; Li, X. Plant natural products: From traditional compounds to new emerging drugs in cancer therapy. Cell Prolif. 2014, 47, 506-515. [CrossRef]

63. Alshatwi, A.A.; Shafi, G.; Hasan, T.N.; Al-Hazzani, A.A.; Alsaif, M.A.; Alfawaz, M.A.; Lei, K.Y.; Munshi, A. Apoptosis-mediated inhibition of human breast cancer cell proliferation by lemon citrus extract. Asian Pac. J. Cancer Prev. 2011, 12, 1555-1559.

64. Luo, G.; Guan, X.; Zhou, L. Apoptotic effect of citrus fruit extract nobiletin on lung cancer cell line A549 In Vitro and In Vivo. Cancer Biol. Ther. 2008, 7, 966-973. [CrossRef] [PubMed]

65. Adewumi Akanji, M.; Demilade Fatinukun, H.; Emmanuel Rotimi, D.; Lawrence Afolabi, B.; Stephen Adeyemi, O. The two sides of dietary antioxidants in cancer therapy. In Antioxidants [Working Title]; IntechOpen: London, UK, 2020. [CrossRef]

66. Boeing, H.; Bechthold, A.; Bub, A.; Ellinger, S.; Haller, D.; Kroke, A.; Leschik-Bonnet, E.; Müller, M.J.; Oberritter, H.; Schulze, M.; et al. Critical review: Vegetables and fruit in the prevention of chronic diseases. Eur. J. Nutr. 2012, 51, 637-663. [CrossRef]

67. Battino, M.; Forbes-Hernández, T.Y.; Gasparrini, M.; Afrin, S.; Cianciosi, D.; Zhang, J.; Manna, P.P.; Reboredo-Rodríguez, P.; Varela Lopez, A.; Quiles, J.L.; et al. Relevance of functional foods in the mediterranean diet: The role of olive oil, berries and honey in the prevention of cancer and cardiovascular diseases. Crit. Rev. Food Sci. Nutr. 2019, 59, 893-920. [CrossRef]

68. Aune, D.; Giovannucci, E.; Boffetta, P.; Fadnes, L.T.; Keum, N.; Norat, T.; Greenwood, D.C.; Riboli, E.; Vatten, L.J.; Tonstad, S. Fruit and vegetable intake and the risk of cardiovascular disease, total cancer and all-cause mortality-A systematic review and dose-response meta-analysis of prospective studies. Int. J. Epidemiol. 2017, 46, 1029-1056. [CrossRef] [PubMed]

69. Brondani, J.E.; Comim, F.V.; Flores, L.M.; Martini, L.A.; Premaor, M.O. Fruit and vegetable intake and bones: A systematic review and meta-analysis. PLoS ONE 2019, 14, e0217223. [CrossRef]

70. Pérez-Bermúdez, P.; Blesa, J.; Soriano, J.M.; Marcilla, A. Extracellular vesicles in food: Experimental evidence of their secretion in grape fruits. Eur. J. Pharm. Sci. 2017, 98, 40-50. [CrossRef] [PubMed]

71. Sagini, K.; Urbanelli, L.; Buratta, S.; Leonardi, L.; Emiliani, C. Nanovesicles from plants as edible carriers of bioactive compounds AgroLife Sci. J. 2017, 6, 167-171.

72. Mohammadinejad, R.; Karimi, S.; Iravani, S.; Varma, R.S. Plant-derived nanostructures: Types and applications. Green Chem. 2016, 18, 20-52. [CrossRef]

73. Iravani, S.; Varma, R.S. Plant-derived edible nanoparticles and MiRNAs: Emerging Frontier for therapeutics and targeted drug-delivery. ACS Sustain. Chem. Eng. 2019, 7, 8055-8069. [CrossRef]

74. Baker, B.P.; Benbrook, C.M.; Groth, E.; Lutz Benbrook, K. Pesticide residues in conventional, integrated pest management (IPM)-grown and organic foods: Insights from three US data sets. Food Addit. Contam. 2002, 19, 427-446. [CrossRef]

75. Cristache, S.-E.; Vuță, M.; Marin, E.; Cioacă, S.-I.; Vuţă, M. Organic versus conventional farming-A paradigm for the sustainable development of the european countries. Sustainability 2018, 10, 4279. [CrossRef] 
76. Barański, M.; Srednicka-Tober, D.; Volakakis, N.; Seal, C.; Sanderson, R.; Stewart, G.B.; Benbrook, C.; Biavati, B.; Markellou, E.; Giotis, C.; et al. Higher antioxidant and lower cadmium concentrations and lower incidence of pesticide residues in organically grown crops: A systematic literature review and meta-analyses. Br. J. Nutr. 2014, 112, 794-811. [CrossRef]

77. Van Dijk, J.P.; Cankar, K.; Scheffer, S.J.; Beenen, H.G.; Shepherd, L.V.T.; Stewart, D.; Davies, H.V.; Wilkockson, S.J.; Leifert, C.; Gruden, K.; et al. Transcriptome analysis of potato tubers-Effects of different agricultural practices. J. Agric. Food Chem. 2009, 57, 1612-1623. [CrossRef]

78. Rempelos, L.; Cooper, J.; Wilcockson, S.; Eyre, M.; Shotton, P.; Volakakis, N.; Orr, C.H.; Leifert, C.; Gatehouse, A.M.R.; Tétard-Jones, C. Quantitative proteomics to study the response of potato to contrasting fertilisation regimes. Mol. Breed. 2013, 31, 363-378. [CrossRef]

79. Benbrook, C. Elevating Antioxidant Levels in Food Through Organic Farming and Food Processing; Center of Education and Promotion, State of Science Review Number 2. Executive summary. 2005. Available online: https:/ /www.organic-center.org/ elevating-antioxidant-levels-food-through-organic-farming-and-food-processing (accessed on 1 May 2021).

80. Ghiselli, A.; Serafini, M.; Natella, F.; Scaccini, C. Total antioxidant capacity as a tool to assess redox status: Critical view and experimental data. Free. Radic. Biol. Med. 2000, 29, 1106-1114. [CrossRef]

81. Marques, S.S.; Magalhães, L.M.; Tóth, I.V.; Segundo, M.A. Insights on antioxidant assays for biological samples based on the reduction of copper complexes-the importance of analytical conditions. Int. J. Mol. Sci. 2014, 15, 11387-11402. [CrossRef] [PubMed]

82. Bartosz, G. Non-enzymatic antioxidant capacity assays: Limitations of use in biomedicine. Free. Radic. Res. 2010, 44, 711-720. [CrossRef]

83. Pinchuk, I.; Shoval, H.; Dotan, Y.; Lichtenberg, D. Evaluation of antioxidants: Scope, limitations and relevance of assays. Chem. Phys. Lipids 2012, 165, 638-647. [CrossRef] [PubMed]

84. Gillman, M.W.; Cupples, L.A.; Gagnon, D.; Posner, B.M.; Ellison, R.C.; Castelli, W.P.; Wolf, P.A. Protective effect of fruits and vegetables on development of stroke in men. JAMA 1995, 273, 1113-1117. [CrossRef]

85. Pellegrini, N.; Serafini, M.; Colombi, B.; Del Rio, D.; Salvatore, S.; Bianchi, M.; Brighenti, F. Total antioxidant capacity of plant foods, beverages and oils consumed in Italy assessed by three different In Vitro assays. J. Nutr. 2003, 133, 2812-2819. [CrossRef]

86. Scandalios, J.G. Oxidative stress: Molecular perception and transduction of signals triggering antioxidant gene defenses. Braz. J. Med. Biol. Res. 2005, 38, 995-1014. [CrossRef]

87. Fang, Y.-Z.; Yang, S.; Wu, G. Free radicals, antioxidants, and nutrition. Nutrition 2002, 18, 872-879. [CrossRef]

88. Yu, L.; Deng, Z.; Liu, L.; Zhang, W.; Wang, C. Plant-derived nanovesicles: A novel form of nanomedicine. Front. Bioeng. Biotechnol. 2020, 8, 584391. [CrossRef] [PubMed] 